\title{
Carbon sequestration potential and its eco-service function in the karst area, China
}

\author{
SONG Xianwei ${ }^{1,2},{ }^{*}$ GAO Yang ${ }^{2,3}$, WEN Xuefa ${ }^{2}$, GUO Dali ${ }^{2}$, YU Guirui ${ }^{2}$, \\ HE Nianpeng ${ }^{2}$, ZHANG Jinzhong ${ }^{1}$ \\ 1. College of Resources and Environment, Southwest University, Chongqing 400716, China; \\ 2. Key Laboratory of Ecosystem Network Observation and Modeling, Institute of Geographic Sciences and \\ Natural Resources Research, CAS, Beijing 100101, China; \\ 3. University of Chinese Academy of Sciences, Beijing 100049, China
}

\begin{abstract}
The karst critical zone is an essential component of the carbon (C) pool, constituting the global $\mathrm{C}$ cycle. It is referred to as one of the "residual land sink" that remains largely indeterminate. Karst area $\left(2.2 \times 10^{7} \mathrm{~km}^{2}\right)$ comprises $15 \%$ of the world's land area, and karst area comprises $3.44 \times 10^{6} \mathrm{~km}^{2}$ of area in China. Due to the complexity of karst structure and its considerable heterogeneity, $\mathrm{C}$ sequestration rate estimations contain large inaccuracies, especially in relation to the different methods used in calculations. Therefore, we reevaluated rock weathering-related $C$ sink estimations in China (approximately $4.74 \mathrm{Tg} \mathrm{C} \mathrm{yr}^{-1}$ ), which we calibrated from previous studies. Additionally, we stipulated that more comprehensive research on rock-soil-biology-atmosphere continuum $C$ migration is essential to better understand $C$ conversion mechanisms based on uncertainty analyses of $C$ sink estimations. Moreover, we stressed that a collective confirmation of chemical methods and simulated models through a combined research effort could at least partially eliminate such uncertainty. Furthermore, integrated $C$ cycling research need a long-term observation of the carbon flux of multi-interfaces. The enhanced capacity of ecosystem $C$ and soil $C$ pools remains an effective way of increasing $C$ sink. Karst ecosystem health and security is crucial to human social development, accordingly, it is critical that we understand thresholds or potential $\mathrm{C}$ sink capacities in karst critical zones now and in the future.
\end{abstract}

Keywords: karst; karst critical zone; carbon sink; carbon sequestration rate; China

\section{Introduction}

Carbon (C) is the core element in ecosystem matter and energy cycling, and C cycle is a key driving factor of global climate change. The World Climate Research Programme (WCRP), the Global Climate Project (GCP), and the International Geosphere-Biosphere Programme (IGBP) have greatly contributed to the evaluation of the global $\mathrm{C}$ cycle. Now, greater atten-

Received: 2016-12-14 Accepted: 2017-01-18

Foundation: National Natural Science Foundation of China, No.41571130043; Youth Innovation Promotion Association, CAS

Author: Song Xianwei (1993-), Master, specialized in ecological hydrology. E-mail: sxwkerry@163.com

*Corresponding author: Gao Yang (1981-), Associate Professor, E-mail: gaoyang@igsnrr.ac.cn 
tion is being paid to research on regional $\mathrm{C}$ sources and sinks and national $\mathrm{C}$ balances and their effect on global climate change (Pan et al., 2011; Gao et al., 2016). Uncertainty in the capacity of $\mathrm{C}$ sinks within the global $\mathrm{C}$ cycle is from 2 to $4 \mathrm{Pg} \mathrm{C} \mathrm{yr}^{-1}$, but these estimations have not considered all the $\mathrm{C}$ sources and sinks related to soil erosion and land-use changes (Schimel et al., 2001; Fang et al., 2004).

Global karst area is approximately $2.2 \times 10^{7} \mathrm{~km}^{2}$, which is $15 \%$ of the planet's land area, and the "residual land sink" of $\mathrm{C}$ is $2.5 \mathrm{Pg} \mathrm{C} \mathrm{yr}^{-1}$, which was estimated by the Fifth Assessment Report (AR5) by the Intergovernmental Panel on Climate Change (IPCC) (Ciais et al., 2013; Pu et al., 2015). In contrast, net $\mathrm{C}$ uptake by terrestrial ecosystems is from 1.0 to 2.6 $\mathrm{Pg} \mathrm{C} \mathrm{yr}^{-1}$, and the rock weathering $\mathrm{C}$ sink capacity is from 0.11 to $0.608 \mathrm{Pg} \mathrm{C} \mathrm{yr}^{-1}$, comprising from $4.4 \%$ to $24.3 \%$ of the residual land $\mathrm{C}$ sink (Liu and Zhao, 2000; Piao et al., 2009; Zhang, 2011). Karst processes do not only have a significant effect on terrestrial C uptake, but also have a strong effect on environmental quality and service functions of ecosystems on a regional scale (Piao et al., 2010; Jiang et al., 2013).

There has been profound discussion on how $\mathrm{CO}_{3}^{2-}-\mathrm{CO}_{2}-\mathrm{H}_{2} \mathrm{O}$ mixed systems act as driving forces (e.g., pumps) in karst areas. The dynamic systems of karst areas are composed of this type of mixed system coupled with C cycling (Yuan and Zhang, 2008; Yan et al., 2011). Moreover, the capacity of karst areas to act as $\mathrm{C}$ sink is considered a significant factor for atmospheric carbon dioxide $\left(\mathrm{CO}_{2}\right)$ removal, and dissolved inorganic carbon (DIC) concentrations in karst water is a key parameter in $\mathrm{C}$ sink evaluations applying conventional methods (Liu, 2011a; Zhang, 2012).

The critical zone (CZ) concept put forward by the earth science community is highly consistent with ecosystem ecology (Richter and Billings, 2015). The CZ concept represents the complex interactions in the rock-soil-water-biology-atmosphere continuum within a heterogeneous soil surface environment, whose most intimate relationship with human survival determines resource allocation and social development demands (Lin, 2010). Furthermore, the $\mathrm{CZ}$ concept describes a vertical wholistic resource and environmental zone from the plant canopy to the bedrock aquifer. The concept of the karst $\mathrm{CZ}$ was put forward based on the strong consistency observed between ecosystems and the $\mathrm{CZ}$ to better understand the concept of "karstification" (Yuan, 2009). Not only does the coupling relationship between water, C, and nutrient cycling play a significant role in terrestrial ecosystems (Gao et al., 2013), but even greater relevant coupling relationships could occur within the karst CZ, which is widely believed to be an extremely unbalanced system.

A brief evaluation of karst distribution around the world has singled out the karst region of China for its significance, urgency, and enormous influence on sustainable agricultural development and ecological restoration. Accordingly, we amassed the numerous methods and models used in this research discipline to review $\mathrm{C}$ sink estimations and, by recalibrating previous estimations, provided a revaluation of the rock weathering $\mathrm{C}$ sink value in China. Following this, we discussed the key uncertainties according to the abundant available researches on integrated $\mathrm{C}$ cycling systems. Lastly, we provided scenarios related to potentially increasing $\mathrm{C}$ sink of the karst $\mathrm{CZ}$ in China. 


\section{Characteristics of geologic distribution and karst structure}

Karst area is mainly distributed throughout East Asia, the Mediterranean coast, and the North American and Caribbean regions. However, between these three territories, karst area is concentrated mostly in East Asia (Durr et al., 2005). Karst area is approximately $344.7 \times 10^{4} \mathrm{~km}^{2}$ and bare carbonate distribution area is $90.7 \times 10^{4} \mathrm{~km}^{2}$, which comprises more than one-third and one-seventh of territorial area in China, respectively (Luo et al., 2014; Song et al., 2016). The southwestern karst zone of China is one of the most concentrated karst areas in the world, which primarily includes the provinces of Guizhou, Yunnan, and the Guangxi Zhuang Autonomous Region.

Multiple zoning methods are used to designate different karst areas in China, which are dependent on different factors. For example, tropical humid karst, subtropical humid karst, subtropical semi-humid karst, temperate arid karst, and plateau cold karst have been subdivided according to weather conditions, while bare karst, soddy karst, and buried karst have been subdivided based on their rock outcrop formations (Figure 1) (Wang et al., 2005; Bai et al., 2009; Jiang et al., 2011).

Distinctive karst landforms were mainly created from the dissolution of carbonite, principally limestone and dolomite. In karst areas, soil is considered a non-renewable resource on account of its slow pedogenesis and strong soil erosion (Long et al., 2005). Moreover, karst aquifers are extremely vulnerable to contamination due to the highly heterogeneous and anisotropic character by their springs, caves, and sinkholes. Weathered layers and corroded soil that result from the hydrological dynamic systems of karst formations exhibit discontinuous distribution characteristics in both vertical and horizontal horizons, which can also be described as soil mosaic distributions and rock outcrops. Subsurface flow moves rapidly due to highly developed underground conduits, and surface runoff coefficients are very low. On the whole, the soil structure and hydrological characteristics of the epikarst is defined as a three-dimensional dualistic structure (Figure 2).

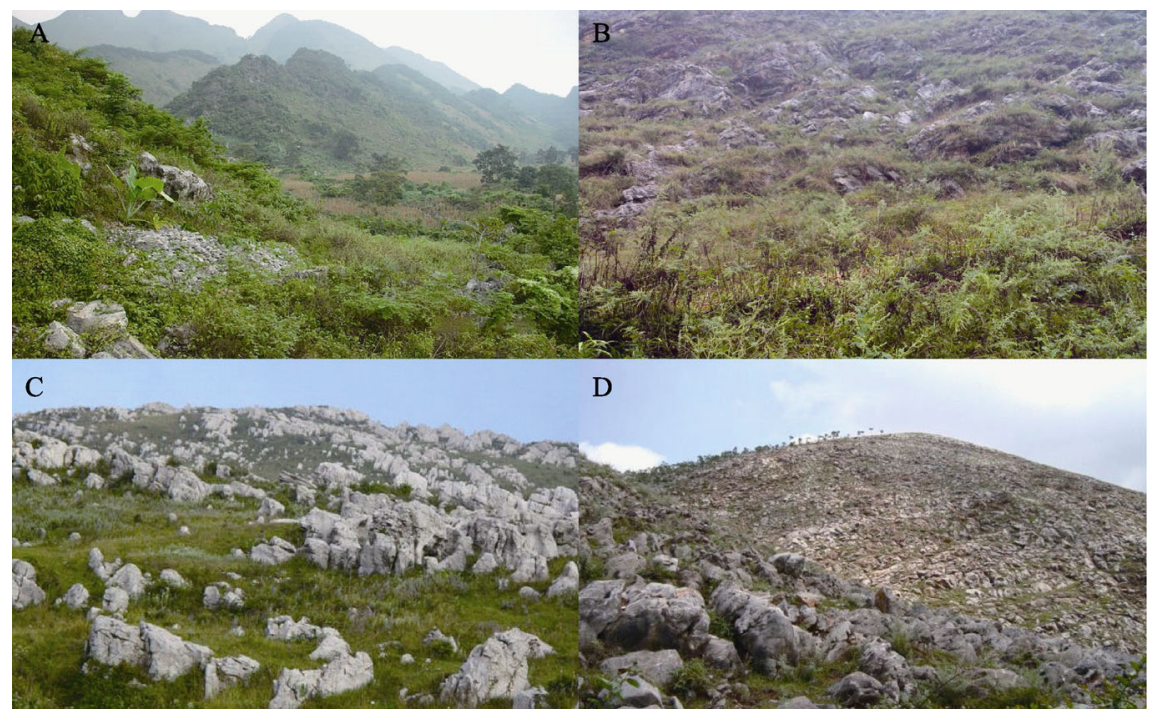

Figure 1 Different erosion degrees of karst topography 


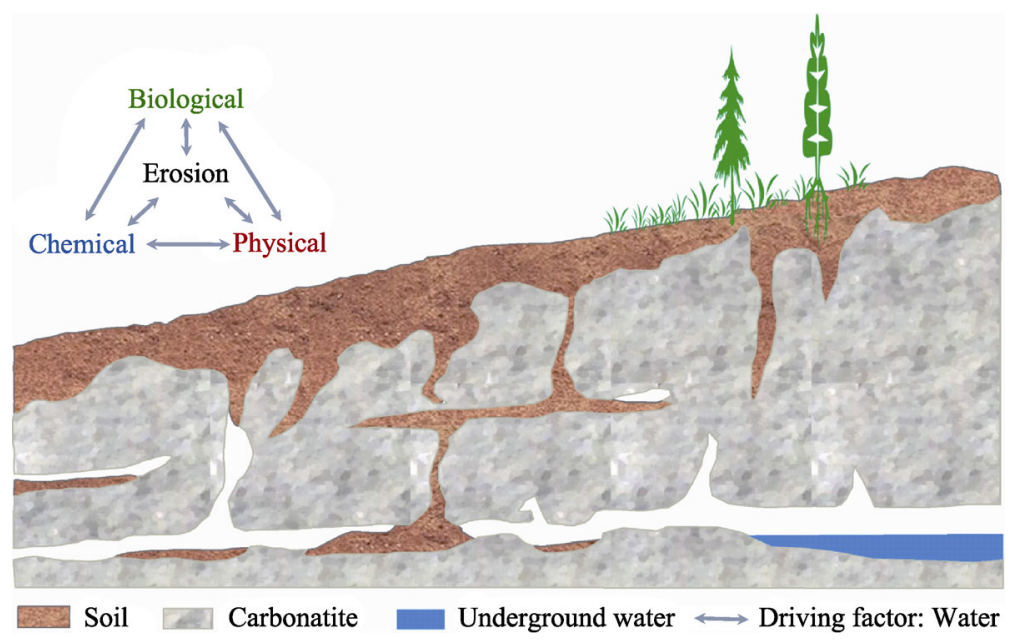

Figure 2 Karst structure controlled by soil erosion and rock weathering

\section{Estimating rock-weathering carbon sink}

\subsection{Estimated methods}

The $\mathrm{C}$ sequestration rate is a parameter used in $\mathrm{C}$ sink evaluations; however, various calculation methods are used and significant uncertainties remained. The reverse approach and forward modeling are two popular $\mathrm{C}$ sink estimation methods used in karst areas. Estimations using the reverse approach are suitable for small watersheds where rock types are clearly known, and hydrochemical relationships between river and rock weathering products are conducted on the basis (Hartmann, 2009). Forward modeling derives from the Temperate Stream Model, which is based on relationships between rock types, rock-weathering rates, and runoff effects (Meybeck, 1987; Suchet and Probst, 1993; Suchet and Probst, 1995; Velbel and Price, 2007). According to numerous studies, the following equation expresses an existing global empirical model on $\mathrm{C}$ uptake rates:

$$
F_{1}=a \sum_{n-1}^{12}\left(q_{s}+q_{u}\right)
$$

where $F_{1}$ represents $\mathrm{C}$ sequestration in a karst area; $q_{s}$ and $q_{u}$ represent the monthly mean flux of surface water and underground water, respectively; $a$ is the empirical parameter dependent on the rock type; and $a$ is $0.0294 \mathrm{~g} \mathrm{C} \mathrm{mm}^{-1}$, estimated by Bluth (Bluth and Kump, 1994), and $0.0383 \mathrm{~g} \mathrm{C} \mathrm{mm}^{-1}$, estimated by Suchet (Suchet and Probst, 1993). By applying this empirical equation to the Houzhai River basin in southwest China, Yan et al. (2011) estimated the value of $\mathrm{C}$ sequestration at $22.3 \mathrm{~g} \mathrm{C} \mathrm{m}^{-2} \mathrm{yr}^{-1}$ and $29.0 \mathrm{~g} \mathrm{C} \mathrm{m}^{-2} \mathrm{yr}^{-1}$, respectively (Yan et al., 2011). This result is inconsistent with other estimated values, primarily because both parameters lack data support in China.

Popular methods used in China are the solute load method, the carbonate-rock-tablet test, the diffusion boundary layer (DBL) theory, model simulations, and the inverse modeling method as well as other methods that derive from the above methods (Liu and Zhao, 2000; Liu et al., 2010; Liu, 2011b; Yan et al., 2011). The solute load method is suitable for C sink estimations of closed and complete drainage basins on a macro scale. This method, however, 
demands a large amount of hydrochemical data and strict conditions. Nevertheless, mixed C forms can still be released from the Earth's interior as well as from exogenous acid effects (Lerman et al., 2007; Gaillardet and Galy, 2008; Hurwitz et al., 2010; Zhang and Li, 2012). Bicarbonate concentrations in surface runoff, groundwater, and water discharge are essential parameters used in estimating $\mathrm{C}$ sequestration rates. Moreover, new monitoring technologies, such as eddy covariance, remote sensing, stable isotope tracers, and GIS-based spatial analysis, are combined in global C cycling observation systems (Cao et al., 2004; Yu et al., 2011). The current challenge remains to combine observational data with multiple models for estimating or forecasting.

Chemical weathering reactions of limestone and dolomite differ as follows:

$$
\begin{gathered}
\mathrm{CaCO}_{3}+\mathrm{CO}_{2}+\mathrm{H}_{2} \mathrm{O} \rightleftharpoons \mathrm{Ca}^{2+}+2 \mathrm{HCO}_{3}^{-} \\
\mathrm{CaMg}\left(\mathrm{CO}_{3}\right)_{2}+2 \mathrm{CO}_{2}+2 \mathrm{H}_{2} \mathrm{O} \rightleftharpoons \mathrm{Ca}^{2+}+\mathrm{Mg}^{2+}+4 \mathrm{HCO}_{3}^{-}
\end{gathered}
$$

The two chemical equations above show that 1 or 2 mols of $\mathrm{CO}_{2}$ would be needed when 1 mol of $\mathrm{CaCO}_{3}$ or $\mathrm{CaMg}\left(\mathrm{CO}_{3}\right)_{2}$ dissolved. Although the $\mathrm{CO}_{2}$ required for rock weathering does not directly derive from the atmosphere (deriving partly from soil), rock weathering $\mathrm{C}$ uptake processes could still be considered an atmospheric $\mathrm{CO}_{2}$ sink because the $\mathrm{CO}_{2}$ released from the soil to the atmosphere will decrease in conjunction with $\mathrm{C}$ uptake rock weathering processes.

The following equation describes the solute load method:

$$
F_{2}=0.5 \times c \times q \times \frac{M_{c}}{M_{\mathrm{HCO}_{3}}}
$$

where $F_{2}$ is the $\mathrm{C}$ sequestration rate; $c$ is the $\mathrm{HCO}_{3}^{-}$concentration in karst runoff; $q$ is water discharge; $M_{c}$ and $M_{\mathrm{HCO}_{3}}$ are the relative molecular mass of $\mathrm{C}$ and $\mathrm{HCO}_{3}^{-}$, respectively. Yan (2011) calculated the $\mathrm{C}$ sequestration rate in the Houzhai River basin within the southwestern karst zone in China using this formula. The result, which derived from surface and subsurface water data from 1986 to 2007, was $20.7 \mathrm{~g} \mathrm{C} \mathrm{m}^{-2} \mathrm{yr}^{-1}$, being much higher than the $8.6 \mathrm{~g} \mathrm{C} \mathrm{m}^{-2} \mathrm{yr}^{-1}$ estimated by Jiang (Jiang and Yuan, 1999; Liu and Zhao, 2000; Yan et al., 2011).

The carbonate-rock-tablet test is suitable for karst areas where no carbonatite overlies soil. This mature method has been widely used for its simple operation and short duration period. At the same time, however, it has limitations, such as representativeness and scale conversions, and this is on account of the vast heterogeneity of karst soil and the diversity in runoff erosion (Liu, 2011b; Zeng et al., 2014). All these issues could cause great differences in final estimations. One hydrologic year is generally required to test weight decreases in the tablet, which is the key information required to calculate $\mathrm{C}$ sequestration.

$$
F=365 \times 10^{4} \times\left(W_{1}-W_{2}\right) \times R \times \frac{M_{c}}{M_{\mathrm{CaCO}_{3}} S T}
$$

where $F$ is the $\mathrm{C}$ sequestration rate $\left(\mathrm{g} \mathrm{C} \mathrm{m}^{-2} \mathrm{yr}^{-1}\right) ; W_{1}-W_{2}$ is the absolute quality of carbonatite corrosion $(\mathrm{g}) ; R$ is the relative content percentage of $\mathrm{CaCO}_{3}$ in the tablet; $S$ is the superficial area of the tablet $\left(\mathrm{cm}^{2}\right) ; T$ is burial time (d). Using this method, Zhang et al. determined the sequestration rate in an order of magnitude from farmland $>$ woodland $>$ cultivated land $>$ fallow land $>$ bush fallow land (Zhang et al., 2006). 


\subsection{Carbon sink evaluation in the karst zone, China}

The global $\mathrm{C}$ sink is $0.8242 \mathrm{Pg} \mathrm{C} \mathrm{yr}^{-1}$, of which the net $\mathrm{C}$ sink is $0.7052 \mathrm{Pg} \mathrm{C} \mathrm{yr}^{-1}$, which was estimated by Liu et al., who took accounted of carbonatite weathering and aquatic organism (Liu et al., 2010). Using the multiple estimation method, the terrestrial ecosystem C sequestration rate was from 0.19 to $0.26 \mathrm{Pg} \mathrm{C} \mathrm{yr}^{-1}$, which converts to $0.26 \mathrm{Pg} \mathrm{C} \mathrm{yr}^{-1}$ using the inverse modeling method (Piao et al., 2009). According to mean bicarbonate ion concentrations and runoff modulus, the $\mathrm{C}$ sink in the karst area of China is $10.09 \mathrm{Tg} \mathrm{C} \mathrm{yr}^{-1}$, estimated using the solute load method (Jiang et al., 2011). However, there exists some deviation in this estimation that must be recalculated (Zhang, 2012; Jiang et al., 2013). Jiang et al. (2013) divided China karst area into four regions, which were the southern karst region, the northern karst region, the Tibetan Plateau karst region, and the buried karst region, and their occupied areas were $5.648 \times 10^{5} \mathrm{~km}^{2}, 3.258 \times 10^{5} \mathrm{~km}^{2}, 5.560 \times 10^{5} \mathrm{~km}^{2}$, and $2.001 \times 10^{6} \mathrm{~km}^{2}$, respectively (Figure 3 and Table 1). We reevaluated $\mathrm{C}$ sink in the karst zone in China by remedying the data of the northern karst and buried karst regions, and we used a correction coefficient $(\mathrm{a}=0.65)$ to eliminate interference from sulfuric acid and nitric acid caused by carbonatite dissolution. As Tables 1 and 2 show, the total $\mathrm{C}$ sink in the karst zone of China is 4.74 $\mathrm{Tg} \mathrm{C} \mathrm{yr}^{-1}$, which is roughly approximate with the estimation reported by Jiang (2013).

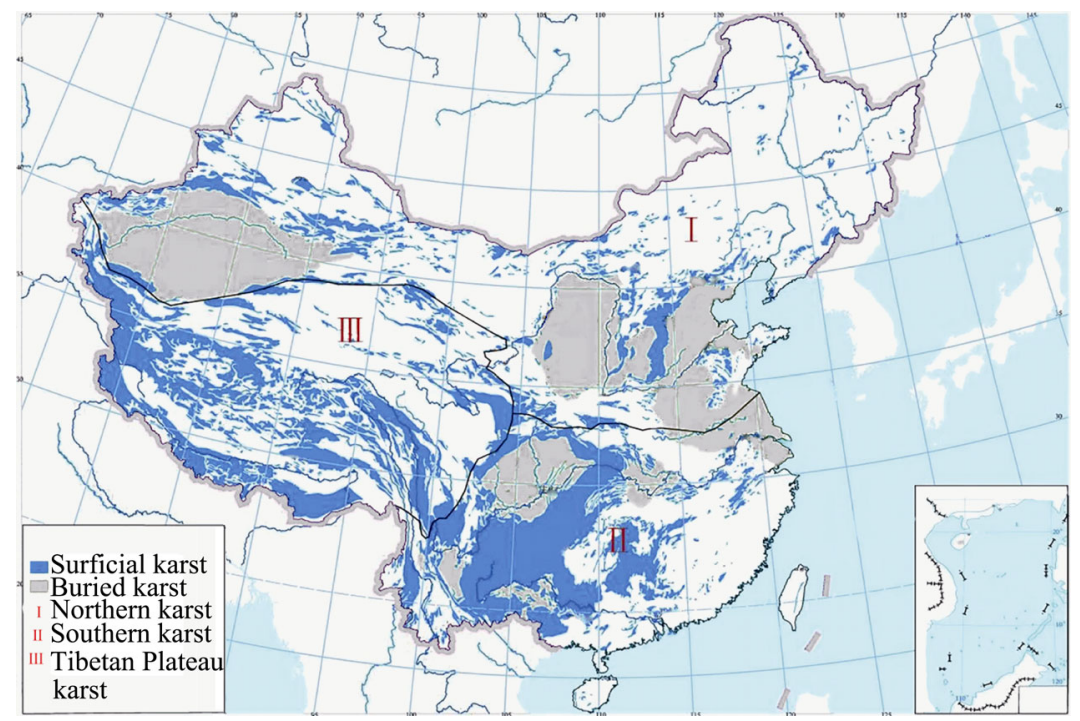

Figure 3 Regions divided of karst type in China

Table $1 \mathrm{CO}_{2}$ sink estimated result in each karst region, China

\begin{tabular}{lccccc}
\hline \multicolumn{1}{c}{ Karst regions } & Area $\left(10^{4} \mathrm{~km}^{2}\right)$ & $\mathrm{HCO}_{3}^{-}\left(\mathrm{g} \mathrm{L}^{-1}\right)$ & $\begin{array}{c}\text { Runoff modulus } \\
\left(10^{7} \mathrm{~L} \mathrm{~km}^{-2} \mathrm{yr}^{-1}\right)\end{array}$ & $\begin{array}{c}\text { Correction } \\
\text { coefficient }\end{array}$ & $\begin{array}{c}\mathrm{CO}_{2} \mathrm{sink}^{-} \\
\left(10^{4} \mathrm{yr}^{-1}\right)\end{array}$ \\
\hline Southern karst & 56.48 & 0.23 & 40.59 & 0.65 & 1241.5 \\
Northern karst & 32.58 & 0.25 & 6.31 & 0.65 & 118.1 \\
Tibetan Plateau karst & 55.60 & 0.15 & 19.95 & 0.65 & 377.0 \\
Buried karst & 200.01 & 0.23 & 0.01 & 0.65 & 1.1 \\
Total & 344.67 & & & 1737.6 \\
\hline
\end{tabular}


Table 2 C sequestration rate of Chinese karst by using different methods

\begin{tabular}{|c|c|c|c|c|}
\hline Estimation method & Study area* & $\begin{array}{c}\text { Average C } \\
\text { sequestration/ } \\
\left(\mathrm{Tg} \mathrm{C} \mathrm{yr}^{-1}\right)\end{array}$ & $\begin{array}{c}\text { Global average } \mathrm{C} \\
\text { sequestration/ } \\
\left(\mathrm{Pg} \mathrm{C} \mathrm{yr}^{-1}\right)\end{array}$ & Data source \\
\hline Solute load method & Bare karst in China & 12 & - & Yan et al., 2011 \\
\hline Solute load method & Bare karst in China & 4.8 & - & Jiang and Yuan, 1999 \\
\hline Carbonate-rock-tablet test & Bare karst in China & 3.2 & - & Jiang and Yuan, 1999 \\
\hline DBL theory (potential C sink) & China & 64.2 & 0.41 & Liu and Zhao, 2000 \\
\hline Solute load method & China & 17.9 & 0.11 & Liu and Zhao, 2000 \\
\hline Carbonate-rock-tablet test & China & 17.5 & 0.11 & Liu and Zhao, 2000 \\
\hline Carbonate-rock-tablet test & China & 3.21 & - & Jiang et al., 2013 \\
\hline Solute load method & China & 4.84 & - & Jiang et al., 2013 \\
\hline $\begin{array}{l}\text { Simple accumulate method } \\
\text { (By province) }\end{array}$ & China & 5.07 & - & Jiang et al., 2013 \\
\hline $\begin{array}{l}\text { GIS-based carbonate-rock- } \\
\text { tablet test }\end{array}$ & China & 3.88 & - & Jiang et al., 2013 \\
\hline GEM-CO ${ }_{2}$ Model & China & 14.1 & - & Qiu et al., 2004 \\
\hline Solute load method & China & 10.09 & - & Li et al., 2014 \\
\hline Comprehensive method & - & - & 0.7052 & Liu et al., 2010 \\
\hline Solute load method & China & 4.74 & - & This research \\
\hline
\end{tabular}

*Bare karst area in China is $0.907 \times 10^{6} \mathrm{~km}^{2}$; Total karst area in China is $3.44 \times 10^{6} \mathrm{~km}^{2}$

\subsection{Models used for $\mathbf{C}$ sink estimations}

There are great differences in the mechanisms, operations, and purposes of terrestrial ecosystem models now. Given that few models have been specifically developed for karst areas, such models face significant challenges and uncertainty. Even the Community Land Model (CLM), one of the most highly developed terrestrial system models, established by the National Center for Atmospheric Research (NCAR) of the United States of America, performed poorly in Tibetan Plateau, China (Luo et al., 2013). Various types of models have been applied in China, such as the Atmosphere-Vegetation Interaction Model (AVIM2); the Carbon Exchange in the Vegetation-Soil-Atmosphere model (CEVSA); the Geoscience Knowledge Integration Protocol (GeoPro) based on $\mathrm{C}$, nitrogen $(\mathrm{N})$, and water coupling system; the Global Erosion Model for $\mathrm{CO}_{2}$ fluxes model $\left(\mathrm{GEM}-\mathrm{CO}_{2}\right)$ based on different weathering coefficients of rocks; the Global Production Efficiency Model (GLO-PEM), Carnegie-AmesStanford Approach (CASA), and GEOLUE models based on the efficiency of photosynthesis and autotrophic respiration; and the Terrestrial Ecosystem Model (TEM) based on eco-models (Suchet and Probst, 1993; Suchet and Probst, 1995; Qiu et al., 2004). Net pri-

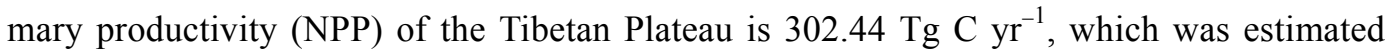
using TEM (Zhou et al., 2004). The 50-year mean Net Ecosystem Productivity (NEP) of Guizhou Province, China, dominated by karst landforms under a semitropical climate, is $23.9 \mathrm{~g} \mathrm{C} \mathrm{m}^{-2} \mathrm{yr}^{-1}$, which was estimated using AVIM2 (Ma et al., 2013). Moreover, this result was roughly one-fifth of the non-karst area in the Qilian Mountains, Qinghai Province, China, which was also estimated using AVIM2. Additionally, GEM-CO $\mathrm{CO}_{2}$ has been used to estimate rock weathering $C$ sink in a karst region in China (Liu et al., 2015). Rock weathering $\mathrm{C}$ sink flux is $14.1 \mathrm{Tg} \mathrm{C} \mathrm{yr}^{-1}$ in China, which was estimated using GEM-CO 
tributions of carbonatite and silicate rocks were $52.65 \%$ and $47.35 \%$, respectively (Qiu et al., 2004). However, there is much work to be done to increase model applicability in karst areas. The combination and mutual authentication of ecosystem $\mathrm{C}$ cycle models, regional scale inversion models, and remote sensing observation systems will provide strong support and greater accuracy in $\mathrm{C}$ sink estimations in karst areas. Discovering how to optimize terrestrial ecosystem models for application in karst ecosystems by adding correction coefficients or redefining model parameters would be a significant step forward.

\section{Uncertainty analysis}

\subsection{Exogenous acids effect on carbonatite corrosions}

Bicarbonate ions can be generated from reactions of nitric acid with carbonatite, and sulfuric acid with carbonatite as well (the exception of carbon acid). As a result, bicarbonate ion concentrations are rather high in karst water. As shown in Eqs. (6) and (7), neither atmospheric $\mathrm{CO}_{2}$ nor soil participated in such reactions. Both the chemical mass balance model and stable isotope analysis confirmed that these processes had a nonnegligible effect on $\mathrm{C}$ sink estimations.

$$
\begin{gathered}
\left(\mathrm{Ca}_{(1-\mathrm{x})} \mathrm{Mg}_{\mathrm{x}}\right) \mathrm{CO}_{3}+\mathrm{HNO}_{3} \rightleftharpoons(1-\mathrm{x}) \mathrm{Ca}^{2+}+\mathrm{xMg}^{2+}+\mathrm{NO}_{3}^{-}+\mathrm{HCO}_{3}^{-} \\
2\left(\mathrm{Ca}_{(1-\mathrm{x})} \mathrm{Mg}_{\mathrm{x}}\right) \mathrm{CO}_{3}+\mathrm{H}_{2} \mathrm{SO}_{4} \rightleftharpoons 2(1-\mathrm{x}) \mathrm{Ca}^{2+}+2 \mathrm{xMg}^{2+}+\mathrm{SO}_{4}^{2-}+2 \mathrm{HCO}_{3}^{-}
\end{gathered}
$$

Yan (2011) found that $\mathrm{Ca}^{2+}, \mathrm{Mg}^{2+}, \mathrm{HCO}_{3}^{-}$, and $\mathrm{SO}_{4}^{2-}$ accounted for $96 \%$ of the total dissolved solids, and the proportion of negative ions from $\mathrm{SO}_{4}^{2-}$ was second only to $\mathrm{HCO}_{3}^{-}$. Moreover, $\mathrm{SO}_{4}^{2-}$ concentrations in water have a direct relationship with its contribution to rock weathering (Yan et al., 2011). Liu (2008) estimated that $\mathrm{CO}_{2}$ released from sulfuric acid-driven carbonatite weathering in southwestern China was $4.4 \mathrm{Tg}^{-1}$; therefore, it was calculated that $28 \mathrm{Tg} \mathrm{yr}^{-1}$ was the $\mathrm{CO}_{2}$ flux released from karst areas in China, which accounted for $33 \%$ of rock weathering $\mathrm{C}$ sink (Liu, 2008). On a smaller scale, results from an agriculture dominant karst catchment within the Qingmuguan subterranean watershed area in Chongqing City, China, showed that DIC produced by sulfuric and nitric acids accounted for $33.8 \%$ of the total DIC in subterranean water, which took up almost the same percentage (Zhang et al., 2012). Additionally, other carbonatite areas showed a slightly smaller influence from sulfuric and nitric acids. In the Yalong River, that drains into the eastern Tibetan Plateau, China, approximately $13 \%$ of DIC originated from sulfuric and nitric acid-driven carbonate weathering (Li et al., 2014). In another small drainage basin of the Qinhe River in northern China, $\mathrm{CO}_{2}$ released from sulfuric acid-driven carbonate weathering was $0.63 \times 10^{5}$ mol km $\mathrm{yr}^{-1}$, which accounted for $44 \%$ of $\mathrm{CO}_{2}$ released by carbonate weathering (Zhang et al., 2015). Thus, applying a 0.35 calibration factor is scientifically-based and appropriate for use in the above reevaluation.

Furthermore, water from non-karst catchments will also directly result in deviations in uncertainty during $\mathrm{C}$ sink evaluations. However, given that the dilution effect is difficult to quantify, this has seldom been considered before. Moreover, spatial scale conversions are one of the most difficult and recurrent problems which cause immeasurable uncertainty in $\mathrm{C}$ sink estimations. 


\subsection{Instability of carbonatite weathering $C$ sequestration}

Many studies have also proposed that carbonate weathering may not lead to a stable $\mathrm{C}$ sink, but silicate weathering can absorb atmospheric $\mathrm{CO}_{2}$ as a net $\mathrm{C}$ sink on a geological timescale (Gaillardet et al., 1999; Larson, 2011; Curl, 2012; Groves et al., 2012). Because the chemical equations (Eqs. (2) and (3)) are reversible, an equal quantity of $\mathrm{CO}_{2}$ will be released when subterranean karst water returns to the surface. Thus, silicate weathering is considered the only way for $\mathrm{C}$ sequestration to occur in these studies.

$$
2 \mathrm{CO}_{2}+3 \mathrm{H}_{2} \mathrm{O}+\mathrm{CaSiO}_{3}=\mathrm{Ca}^{2+}+2 \mathrm{HCO}_{3}^{-}+\mathrm{H}_{4} \mathrm{SiO}_{4}
$$

Like Eq. (8) shows, $\mathrm{CO}_{2}$ sequestrated by silicate weathering could be transported into oceans and then settle as carbonate, which results in stable, long-term $\mathrm{C}$ sequestration storage in the duration of millions of years (Berner et al., 1983). $\mathrm{CO}_{2}$ consumption rates of global silicate weathering are from 9.86 to $14.01 \times 10^{12} \mathrm{~mol} \mathrm{yr}^{-1}$, which was deduced through the chemistry of large rivers (Gaillardet et al., 1999; Moon et al., 2014).

At the same time, other studies have shown that $\mathrm{HCO}_{3}^{-}$will not deliver all $\mathrm{CO}_{2}$ back to the atmosphere. Biological cycling could increase both rates and the stability of rock weathering $\mathrm{C}$ sequestration. Moreover, biological behavior can participate in carbonate weathering processes both directly and indirectly. Carbonatite dissolution can be raised one order of magnitude by means of carbonic anhydrase. Additionally, $88 \%$ of $\mathrm{C}$ uptake from photosynthetic processes of aquatic plants derives from water; and particulate organic carbon (POC) uptake by aquatic organisms is also an important means of C sequestration (Liu, 2001; Lian et al., 2011; de Montety et al., 2011). Liu (2010) estimated that the terrestrial aquatic ecosystem contributes $0.2334 \mathrm{Pg} \mathrm{C} \mathrm{yr}^{-1}$ or $33.1 \%$ of the net sink of carbonate dissolution, the global water cycle, and photosynthetic uptake by aquatic organisms (Liu et al., 2010). Therefore, $\mathrm{C}$ emission from rock weathering can be sequestrated by multiple means.

\section{Karst critical zone service functions}

\subsection{Potential increases in $\mathrm{C}$ sink processes}

With the exception of rock weathering $\mathrm{C}$ sink, many other processes could also result in $\mathrm{CO}_{2}$ fixation in the karst critical zone. Unlike non-karst areas, both soil-plant organic processes and biological pump processes, under a precondition of high DIC concentrations in karst water, could result in significant differences.

In conjunction with global climate change, the $\mathrm{C}$ sink from carbonatite weathering is predicted to increase by $21 \%$ to $0.18 \mathrm{Pg} \mathrm{C} \mathrm{yr}^{-1}$ (Liu et al., 2010). However, not only feedback mechanisms of global ecosystems but also anthropogenic activities can provide means for $\mathrm{C}$ sink management. In the past 50 years, for example, a large bicarbonate flux increased in the Mississippi River, the United States of America, mainly due to land-use changes and management (Raymond et al., 2008). At the same time, it has also been demonstrated that groundwater is a $\mathrm{CO}_{2}$ sink because limestone weathering has caused a $20 \%$ increase in groundwater $\mathrm{CO}_{2}$ concentrations (Macpherson et al., 2008).

The favorable succession order of karst vegetation is bare rock with sparse grass $>$ grassland $>$ scrub-grassland $>$ scrub $>$ liana-scrubland $>$ broad deciduous forests $>$ climax commu- 
nity. However, the path of succession could be more complex in consideration of different conditions of soil, climate, species reproduction strategies, internal community environments, and anthropogenic interference. Saltational evolution could occur under artificial restoration, and reverse succession could occur under anthropogenic disturbances. Previous studies have shown that ecological restoration and land-use pattern conversions could enhance the capacity of $\mathrm{C}$ sinks in karst areas. Dissolution rates of different land utilization types showed significant differences, and subterranean $\mathrm{C}$ sinks of primary forests were three times greater than that of secondary forests and nine times greater than that of scrubland. After conversion from cultivated land and scrubland to secondary forests, $\mathrm{C}$ sinks can increase by 5.71-7.02 $\mathrm{g} \mathrm{C} \mathrm{m}^{-2} \mathrm{yr}^{-1}$ after conversion from cultivated land and scrubland to secondary forests, and will increase by $24.86-26.17 \mathrm{~g} \mathrm{C} \mathrm{m}^{-2} \mathrm{yr}^{-1}$ if those lands could develop into primary forests (Zhang, 2011).

Therefore, based on the discussion above, land-use strategy optimization and ecosystem restoration are efficient ways to increase $\mathrm{C}$ sink in the karst critical zone. To increase karst $\mathrm{C}$ sink under an integrate framework, it is indispensable that researchers get a comprehensive understanding of the rock-soil-biology-atmosphere continuum. In China, a series of policies, such as afforestation, which converts farmland back to forests, and ecomigration have been applied for karst critical zone restoration. However, NPP is considered only a short-term solution for $\mathrm{C}$ sequestration in terrestrial ecosystems, and there are limitations in increasing $\mathrm{C}$ sink in a fragile karst system due to the equilibrium of the carbon-nitrogen- water coupling relationship (Tao et al., 2001; Tao et al., 2003; Gao et al., 2014). To date, an increase in biomass remains an efficient $\mathrm{C}$ sink strategy under vegetation degradation in the karst critical zone. However, this will cause a significant and undefined issue, that is, the determination of the actual $\mathrm{C}$ sink threshold.

Another way to increase $\mathrm{C}$ sink capacities is reducing soil loss. However, due to its thin and spare soil layer, $\mathrm{C}$ sequestration in karst soil is smaller than in non-karst soil. At the same time, reducing soil loss can foster forward vegetation succession, which may promote a virtuous cycle (Figure 4).

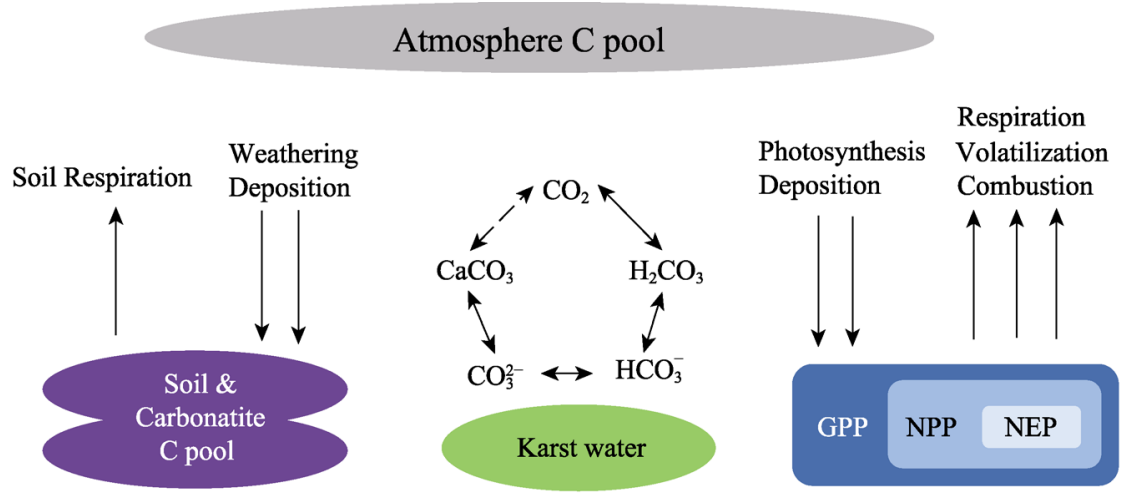

Weathering: Carbonatite and silicate weathering; Respiration: Plant, animal \& microorganism; Combustion: Burning inorganic carbonaceous gas; Volatilization: Biogenic volatile organic compound (VOC); Deposition: Dissolved carbon, particulate carbon

Figure 4 Carbon translation during pools of karst area 


\subsection{Eco-service functions of karst critical zone}

The critical zone (CZ) is a holistic framework for integrated studies of water in conjunction with soil, rocks, air, and biotic resources in near-surface terrestrial environments (Lin, 2010). Karst CZ focuses on the rock-soil-biology-atmosphere continuum, which is characterized by three-dimensional and dualistic structures. The soil ecosystem is the core of the karst CZ, which interacts with the surface crust (vegetation, bedrock, and groundwater) through rock weathering and runoff erosion.

Karst areas have developed conduit systems include natural rock fractures, cenotes, and funnels at macroscopic scale, and soil pore and vascular bundle at microcosmic scale. Matter and energy transport through karst conduit systems are mainly in the form of solute transport. In terms of soil-atmosphere interfacial processes, interaction and feedback mechanisms between photosynthesis and transpiration are mainly dominated by stomatal behavior, which is sensitive to available soil water content. In terms of the soil-root system interface, how rhizospheric microorganisms obtain $\mathrm{C}$ depends on root exudates and degradable organic matter in surface soil.

Furthermore, NPP is the core assessment index of ecosystem service functions and vegetation activity. Ecosystem $\mathrm{C}$ cycle is a representation of the close correlation between biology and abiotic systems. Gao et al. (2013) reported that the carbon-nitrogen-water coupling cycle relationship dominates the $\mathrm{C}$ thresholds and balances of soil ecosystems. According to the $\mathrm{C}$ mass balance model, this relationship may cause excessive $\mathrm{C}$ uptake by karst ecosystem during rock weathering process, and surplus $\mathrm{C}$ loss will occur via soil erosion or other ecological processes.

\section{Prospective}

Accurately and synthetically estimating $\mathrm{C}$ sinks in karst areas is an issue on the frontier of our knowledge and is also an obstacle in $\mathrm{C}$ cycling research in terrestrial ecosystems. From the perspective of karst ecosystems, research on $\mathrm{C}$ sequestration pathways and biological mechanisms remains a fundamental task that is far from completed. Of which, DIC uptake efficiency by aquatic organisms via photosynthetic processes (also referred to as the "biological pump") plays an important role in C sequestration in the karst critical zone. From a research standpoint based on quantification, a number of methods should be combined or performed simultaneously to mutually confirm and thereby generate accurate results. Moreover, the threshold or potential $\mathrm{C}$ sink capacity of the karst $\mathrm{CZ}$ also needs to be quantified for ecosystem health and security.

\section{References}

Bai Xiaoyong, Wang Shijie, Chen Qiwei et al., 2009. Spatio-temporal evolution process and its evaluation method of karst rocky desertification in Guizhou province. Acta Geographica Sinica, 64(5): 609-618. (in Chinese)

Berner R A, Lasaga A C, Garrels R M, 1983. The carbonate-silicate geochemical cycle and its effect on atmospheric carbon-dioxide over the past 100 million years. American Journal of Science, 283: 641-683.

Bluth G J S, Kump L R, 1994. Lithologic and climatologic controls of river chemistry. Geochimica et Cosmochimica Acta, 58: 2341-2359.

Cao Mingkui, Yu Guirui, Liu Jiyuan et al., 2004. Multi-scale observation and cross-scale mechanistic modeling 
on terrestrial ecosystem carbon cycle. Science in China Series D: Earth Sciences, 34(Suppl. 2): 1-14. (in Chinese)

Ciais P, Sabine C, Bala G et al., 2013. Carbon and other biogeochemical cycles. In: Stocker T F, Qin D, Plattner G K et al., Climate Change 2013: The Physical Science Basis. Contribution of Working Group I to the Fifth Assessment Report of the Intergovernmental Panel on Climate Change. Cambridge, United Kingdom and New York, NY, USA: Cambridge University Press, 465-570.

Curl R L, 2012. Carbon Shifted But Not Sequestered. Science, 335: 655-655.

Dürr H H, Meybeck M, Dürr S H, 2005. Lithologic composition of the Earth's continental surfaces derived from a new digital map emphasizing riverine material transfer. Global Biogeochemical Cycles, 19(4): 49-53.

Fang Huajun, Yang Xueming, Zhang Xiaoping et al., 2004. Effect of soil erosion on soil organic carbon in cropland landscape. Progress in Geography, 23(2): 77-87. (in Chinese)

Gaillardet J, Dupre B, Louvat P et al., 1999. Global silicate weathering and $\mathrm{CO}_{2}$ consumption rates deduced from the chemistry of large rivers. Chemical Geology, 159: 3-30.

Gaillardet J, Galy A, 2008. Atmospheric science: Himalaya-carbon sink or source? Science, 320: 1727-1728.

Gao Y, Yu G R, He N P, 2013. Equilibration of the terrestrial water, nitrogen, and carbon cycles: Advocating a health threshold for carbon storage. Ecological Engineering, 57: 366-374.

Gao Y, Yu G R, Yang T T et al., 2016. New insight into global blue carbon estimation under human activity in land-sea interaction area: a case study of China. Earth-Science Reviews, 159: 36-46.

Gao Y, Zhu X J, Yu G R et al., 2014. Water use efficiency threshold for terrestrial ecosystem carbon sequestration in China under afforestation. Agricultural and Forest Meteorology, 195: 32-37.

Groves C, Cao J, Zhang C, 2012. Carbon shifted but not sequestered response. Science, 335: 655-655.

Hartmann J, 2009. Bicarbonate-fluxes and $\mathrm{CO}_{2}$-consumption by chemical weathering on the Japanese Archipelago: Application of a multi-lithological model framework. Chemical Geology, 265: 237-271.

Hurwitz S, Evans W C, Lowenstern J B, 2010. River solute fluxes reflecting active hydrothermal chemical weathering of the Yellowstone Plateau Volcanic Field, USA. Chemical Geology, 276: 331-343.

Jiang Z C, Yuan D X, 1999. $\mathrm{CO}_{2}$ source-sink in karst processes in karst areas of China. Episodes, 22: 33-35.

Jiang Zhongcheng, Qin Xiaoqun, Cao Jianhua et al., 2011. Calculation of atmospheric $\mathrm{CO}_{2}$ sink formed in karst progresses of the karst divided regions in China. Carsologica Sinica, 30(4): 363-367. (in Chinese)

Jiang Zhongcheng, Qin Xiaoqun, Cao Jianhua et al., 2013. Significance and carbon sink effects of karst processes in global carbon cycle: Also reply to "Discussion on article "Calculation of atmospheric $\mathrm{CO}_{2}$ sink formed in karst processes of karst-divided regions in China'”. Carsologica Sinica, 32(1): 1-6. (in Chinese)

Jiang, Z C, Lian Y Q, Qin X Q, 2013. Carbon cycle in the epikarst systems and its ecological effects in South China. Environmental Earth Sciences, 68: 151-158.

Larson, C, 2011. An unsung carbon sink. Science, 334: 886-887.

Lerman A, Wu L L, Mackenzie F T, 2007. $\mathrm{CO}_{2}$ and $\mathrm{H}_{2} \mathrm{SO}_{4}$ consumption in weathering and material transport to the ocean, and their role in the global carbon balance. Marine Chemistry, 106: 326-350.

Li S L, Chetelat B, Yue F J et al., 2014. Chemical weathering processes in the Yalong River draining the eastern Tibetan Plateau, China. Journal of Asian Earth Sciences, 88: 74-84.

Lian Bin, Yuan Daoxian, Liu Zaihua, 2011. Effect of microbes on karstification in karst ecosystems. Chinese Science Bulletin, 56(26): 2158-2161. (in Chinese)

Lin H, 2010. Earth's Critical Zone and hydropedology: Concepts, characteristics, and advances. Hydrology and Earth System Sciences, 14: 25-45.

Liu Congqiag, Jiang Yingkui, Tao Faxiang et al., 2008. Chemical weathering of carbonate rocks by sulfuric acid and the carbon cycling in Southwest China. Geochimica, 37(4): 404-414. (in Chinese)

Liu Yarong, Jia Wenxiong, Huang Wen et al., 2015. Response of vegetation net primary productivity to climate change in the Qilian Mountains since recent 51 years. Acta Botanica Boreali-Occidentalia Sinica, 35(3): 601-607. (in Chinese)

Liu Z, Zhao J, 2000. Contribution of carbonate rock weathering to the atmospheric $\mathrm{CO}_{2}$ sink. Environmental Geology, 39: 1053-1058. 
Liu Zaihua, 2001. The role of carbonic anhydrase as an activator in carbonate rock dissolution and its significance in atmospheric $\mathrm{CO}_{2}$ precipitation. Acta Geoscientia Sinica, 22(5): 477-480. (in Chinese)

Liu Zaihua, 2011a. Is pedogenic carbonate an important atmospheric $\mathrm{CO}_{2}$ sink? Chinese Science Bulletin, 56(26): 2209-2211. (in Chinese)

Liu Zaihua, 2011b. "Method of maximum potential dissolution" to calculate the intensity of karst process and the relevant carbon sink: With discussions on methods of solute load and carbonate-rock-tablet test. Carsologica Sinica, 30(4): 379-382. (in Chinese)

Liu Z H, Dreybrodt W, Wang H J, 2010. A new direction in effective accounting for the atmospheric $\mathrm{CO}_{2}$ budget: Considering the combined action of carbonate dissolution, the global water cycle and photosynthetic uptake of DIC by aquatic organisms. Earth-Science Reviews, 99: 162-172.

Long Jian, Jiang Xinrong, Deng Qiqiong et al., 2005. Characteristics of soil rocky desertification in the karst region of Guizhou province. Acta Pedologica Sinica, 42(3): 419-427. (in Chinese)

Luo Lihui, Zhang Yaonan, Zhou Jian et al., 2013. Simulation and application of the land surface model CLM driven by WRF in the Tibetan Plateau. Journal of Glaciology and Geocryology, 35(3): 553-564. (in Chinese)

Luo Weijun, Wang Shijie, Liu Xiuming, 2014. Research progresses and prospect of chimney effect about carbon cycle in the karst cave system. Advances in Earth Science, 29(12): 1333-1340. (in Chinese)

Ma Jianyong, Gu Xiaoping, Huang Mei et al., 2013. Temporal-spatial distribution of net ecosystem productivity in Guizhou during the recent 50 years. Ecology and Environment, 22(9): 1462-1470. (in Chinese)

Macpherson G L, Roberts J A, Blair J M et al., 2008. Increasing shallow groundwater $\mathrm{CO}_{2}$ and limestone weathering, Konza Prairie, USA. Geochimica et Cosmochimica Acta, 72: 5581-5599.

Meybeck M, 1987. Global chemical-weathering of surficial rocks estimated from river dissolved loads. American Journal of Science, 287: 401-428.

Montety V D, Martin J B, Cohen M J et al., 2011. Influence of diel biogeochemical cycles on carbonate equilibrium in a karst river. Chemical Geology, 283: 31-43.

Moon S, Chamberlain C P, Hilley G E, 2014. New estimates of silicate weathering rates and their uncertainties in global rivers. Geochimica et Cosmochimica Acta, 134: 257-274.

Pan Y D, Birdsey R A, Fang J Y et al., 2011. A large and persistent carbon sink in the world's forests. Science, 333: 988-993.

Piao S L, Ciais P, Huang Y et al., 2010. The impacts of climate change on water resources and agriculture in China. Nature, 467: 43-51.

Piao S L, Fang J Y, Ciais P et al., 2009. The carbon balance of terrestrial ecosystems in China. Nature, 458: 1009-1013.

$\mathrm{Pu}$ Junbing, Jiang Zhongcheng, Yuan Daoxian et al., 2015. Some opinions on rock-weathering-related carbon sinks from the IPCC Fifth Assessment Report. Advances in Earth Science, 30(10): 1081-1090. (in Chinese)

Qiu Dongsheng, Zhuang Dafang, Hu Yunfeng et al., 2004. Estimation of carbon sink capacity caused by rock weathering in China. Earth Science, 29(2): 177-182. (in Chinese)

Raymond P A, Oh N H, Turner R E et al., 2008. Anthropogenically enhanced fluxes of water and carbon from the Mississippi River. Nature, 451: 449-452.

Richter D D, Billings S A, 2015. 'One physical system': Tansley’s ecosystem as Earth's critical zone. New Phytologist, 206: 900-912.

Schimel D S, House J I, Hibbard K A et al., 2001. Recent patterns and mechanisms of carbon exchange by terrestrial ecosystems. Nature, 414: 169-72.

Song Xianwei, Gao Yang, Wen Xuefa et al., 2016. Rock-weathering-related carbon sinks and associated ecosystem service functions in the karst critical zone in China. Acta Geographica Sinica, 71(11): 1926-1938. (in Chinese)

Suchet P A, Probst J L, 1993. Modeling of atmospheric $\mathrm{CO}_{2}$ consumption by chemical-weathering of rocks: Application to the Garonne, Congo and Amazon Basins. Chemical Geology, 107: 205-210.

Suchet P A, Probst J L, 1995. A global model for present-day atmospheric/soil $\mathrm{CO}_{2}$ consumption by chemical erosion of continental rocks (GEM-CO 2 ). Tellus Series B: Chemical and Physical Meteorology, 47: $273-280$. 
Tao Bo, Ge Quansheng, Li Kerang et al., 2001. Progress in the studies on carbon cycle in terrestrial ecosystem. Geographical Research, 20(5): 564-575. (in Chinese)

Tao Bo, Li Kerang, Shao Xuemei et al., 2003. Temporal and spatial pattern of net primary production of terrestrial ecosystems in China. Acta Geographica Sinica, 58(3): 372-380. (in Chinese)

Velbel M A, Price J R, 2007. Solute geochemical mass-balances and mineral weathering rates in small watersheds: Methodology, recent advances, and future directions. Applied Geochemistry, 22: 1682-1700.

Wang Delu, Zhu Shouqian, Huang Baolong et al., 2005. Preliminary study on types and quantitative assessment of Karst rocky desertification in Guizhou Province, China. Acta Ecologica Sinica, 25(5): 1057-1063. (in Chinese)

Yan J H, Wang Y P, Zhou G et al., 2011. Carbon uptake by karsts in the Houzhai Basin, southwest China. Journal of Geophysical Research, 116: 327-336.

Yu Guirui, Wang Qiufeng, Zhu Xianjin, 2011. Methods and uncertainties in evaluating the carbon budgets of regional terrestrial ecosystems. Progress in Geography, 30(1): 103-113. (in Chinese)

Yuan Daoxian, Zhang Cheng, 2008. Karst dynamics theory in China and its practice. Acta Geoscientia Sinica, 29(3): 355-365. (in Chinese)

Yuan Daoxian, 2009. Challenges and opportunities for karst research of our country under the new situation. Carsologica Sinica, 28(4): 329-331. (in Chinese)

Zeng Cheng, Zhao Min, Yang Rui et al., 2014. Comparison of karst processes-related carbon sink intensity calculated by carbonate rock tablet test and solute load method: A case study in the Chenqi karst spring syste. Hydrogeology and Engineering Geology, 41(1): 106-111. (in Chinese)

Zhang Cheng, 2011. Carbonate rock dissolution rates in different landuses and their carbon sink effect. Chinese Science Bulletin, 56(35): 2174-2180. (in Chinese)

Zhang Cheng, Xie Yunqiu, Lü Yong et al., 2006. Impact of land- use patterns upon karst processes: Taking Nongla Fengcong depression area in Guangxi as an example. Acta Geographica Sinica, 61(11): 1181-1188. (in Chinese)

Zhang Dong, Qin Yong, Zhao Zhiqi, 2015. Chemical weathering of carbonate rocks by sulfuric acid on small basin in North China. Acta Scientiae Circumstantiae, 35(11): 3568-3578. (in Chinese)

Zhang Hongming, Li Shuguang, 2012. Deep carbon recycling and isotope tracing: Review and prospect. Science China: Earth Sciences, 42(10): 1459-1472. (in Chinese)

Zhang Xingbo, Jiang Yongjun, Qiu Shulan et al., 2012. Agricultural activities and carbon cycling in karst areas in Southwest China: Dissolving carbonate rocks and $\mathrm{CO}_{2}$ sink. Advances in Earth Science, 27(4): 466-476. (in Chinese)

Zhang Zhigan, 2012. Discussion on article "Calculation of atmospheric $\mathrm{CO}_{2}$ sink formed in karst processes of karst-divided regions in China”. Carsologica Sinica, 31(3): 339-344. (in Chinese)

Zhou Caiping, Ou Yanghua, Wang Qinxue et al., 2004. Estimation of net primary productivity in Tibetan Platea. Acta Geographica Sinica, 59(1): 74-79. (in Chinese) 